\title{
Immunological aspects of asthma
}

\author{
H. E. Amos \\ M.B., B.S., Ph.D. \\ Department of Pathology, University of Cambridge
}

Professor SCADding's definition of asthma (Scadding, 1969) i.e. 'a condition characterized by variable dyspnoea with wheezing and prolonged expiration wholly or partially reversed by bronchodilators', is a clinical definition. It would be premature at this stage to attempt to define asthma in relation to its pathogenesis as this is still not understood. For the purpose of this symposium, however, I would like to present firstly asthma as an immunological disease and secondly, as a condition in which the intrinsic and extrinsic types have the same underlying abnormality.

\section{Evidence for immunological involvement in asthma}

The tissue damage seen in the lungs during a paroxysm of dyspnoea are shown at the microscopic level in Fig. 1. It can be seen that the lumen of the small 2-5 mm bronchus is filled with mucus and cell debris. The cellular infiltration consists mainly of eosinophils. Neutrophils are also present and these may be particularly dense if there is a concurrent infection. Goblet cells in the submucosa are increased in number and there are islands of epithelial regeneration. If the disease is long-standing the basement membrane becomes thickened and the smooth muscle surrounding the bronchi increases in thick $\overrightarrow{0}$ ness. Oedema and vessel dilatation are also presentThus there is suggestive evidence in the histopathos logy of an allergic element to the disease.

Other evidence in favour of an immunologicas involvement includes the relationship between the induction of an asthmatic attack and unusual environmental antigens like castor bean (Figley Elrod, 1928), the close seasonal correlation with grass? pollens and the evidence afforded by provocatios test with aerosol extracts (Lowell \& Schiller, 1948)

\section{The hypersensitivity reaction in asthma}

The incrimination of immunological mechanism\$ in asthma implies that in the first instance the patieng must become sensitized to the allergen: this phase does not manifest as a clinical disease. Further cơntact with the allergen produces a hypersensitivity reaction which leads to tissue damage and cliniogo symptoms. Coombs \& Gell (1963) classified the clinical results of hypersensitivity reactions into foug types of allergic mechanism. These are illustrated if Fig. 2. Historically asthma has been linked with Type 1. In this reaction a specialized class of antibody $i \overrightarrow{\widehat{\sigma}}$ produced which has affinity for certain target cells?

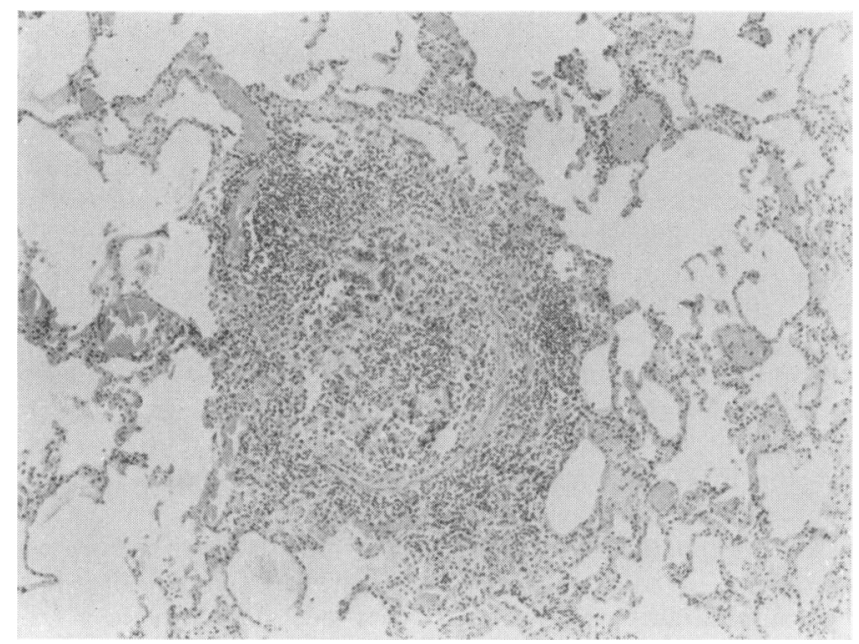

Fig. 1. Histology section of the lung from patient dying in status asthmaticus. 

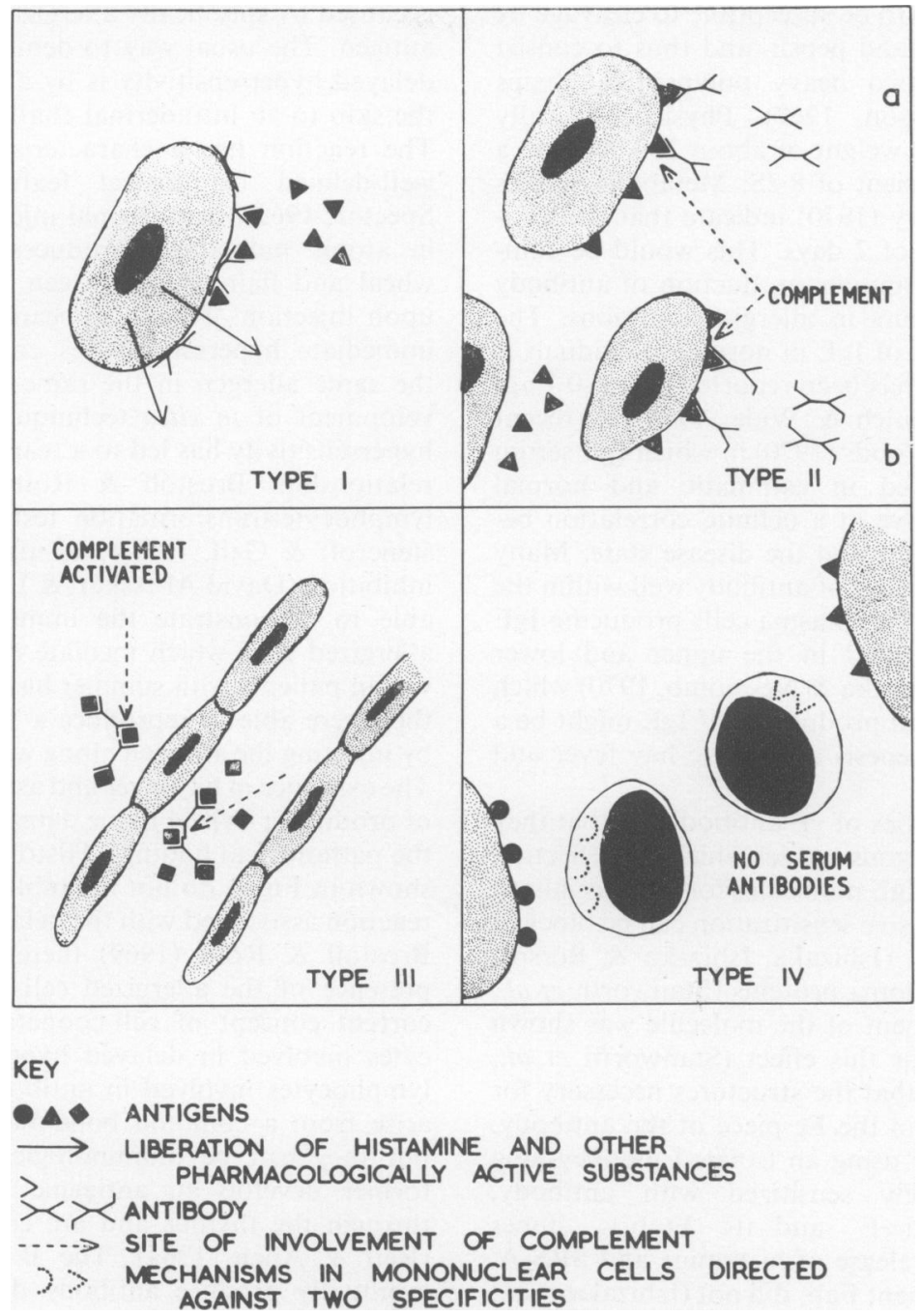

FIG. 2. Types of allergic mechanisms underlying hypersensitivity tissue damage. (Reproduced with permission, from Clinical Aspects of Immunology, edited by P. G. N: Gell \& R. R. A. Coombs, Blackwell Scientific Publications, Oxford.)

The antibodies are termed reagins. When antigen/ antibody combination takes place on the surface of the passively sensitized cell, a biochemical sequence is started which leads eventually to the release of histamine and other mediators. Although substances such as histamine, 5-hydroxytryptamine (5-HT), slow reacting substance-A (SRS-A), kinins and prostaglandins can be shown in in vitro systems to be released by antigen/antibody interactions, conclusive evidence of their role in atopic diseases is lacking.
Perhaps the most significant advance in relation to Type 1 hypersensitivity is the identification of the reaginic antibody. A serum protein was isolated from the sera of atopic patients and shown to carry reaginic activity (Ishizaka, Ishizaka \& Hornbrook, 1966). It was later shown to be an immunoglobulin distinct from the already known classes and designated IgE (Ishizaka, Ishizaka \& Terry, 1967). The finding of a myeloma protein (Johansson \& Bennich, 1967) which cross-reacted with IgE greatly accelerated the work on its structure and properties. The 
molecule was shown to be susceptible to cleavage by the enzymes papain and pepsin and thus to consist of two light and two heavy polypeptide chains (Bennich \& Johansson, 1967). Physicochemically IgE has a molecular weight of about 200,000 and a sedimentation coefficient of 8.2S. Metabolic studies by Waldman \& Terry (1970) indicate that the antibody has a half-life of 2 days. This would be compatible with the continuous production of antibody which probably occurs in allergic conditions. The serum concentration of IgE in normal individuals is very low. The range has been reported as $0 \cdot 1-0 \cdot 7 \mu \mathrm{g} /$ $\mathrm{ml}$ (Johansson, Bennich \& Wide, 1968). A recent survey by Rowe \& Woods (1970) in which IgE serum levels were measured in asthmatic and normal children did not arrive at a definite correlation between raised IgE levels and the disease state. Many atopic patients had levels of antibody well within the normal range. However, plasma cells producing IgE have been demonstrated in the upper and lower respiratory tract (Ishizaka \& Newcomb, 1970) which suggests that the local production of IgE might be a factor in the pathogenesis of allergic hay fever and asthma.

One of the properties of $\gamma \mathrm{E}$ antibodies is that they can sensitize homologous species which is a reflection of the affinity of the IgE molecules for the specialized target cells. Such passive sensitization can be blocked by non-antibody $\gamma E$ (Ishizaka, Ishizaka \& Borsos, 1961) and by E myeloma proteins (Stanworth et al., 1967). The Fc fragment of the molecule was shown to be responsible for this effect (Stanworth et al., 1968) which means that the structures necessary for skin fixation reside in the Fc piece of the antibody. In vitro experiments using an isolated monkey-lung preparation passively sensitized with antibody, showed that anti- $\gamma E$ and its $F\left(a b^{\prime}\right)_{2}$ dimer brought about the release of histamine and SRS-A. The monomer fragment Fab' did not (Ishizaka et al., 1970). The conclusion drawn from these experiments was that complement is not essential for the reaction, as $\mathrm{F}\left(\mathrm{ab}^{\prime}\right)_{2}$ has no complement-fixing activity and that $\gamma E$ antibody is needed to bridge two IgE molecules on the target cells for the induction of the reaction. In other words IgE is divalent. A further important finding which may be very relevant in asthma is that circulating basophils from atopic subjects have IgE on their membranes (Ishizaka, Tomioka \& Ishizaka, 1970). The role of basophils in asthma is not clear but it is conceivable that a continuous supply of the cells from the circulation migrating into the local site of action, could potentiate and prolong the atopic symptoms.

Until recently, delayed hypersensitivity was believed to play no part in atopic disease. Reference to Fig. 2 shows that delayed hypersensitivity does not involve serum antibodies. Instead, the tissue damage is caused by specifically allergized cells reacting wit antigen. The usual way to demonstrate the state delayed hypersensitivity is by a reaction induced i the skin to an intradermal challenge of the antigen: The reaction has a characteristic time-course and well-defined histological features (Boughton Spector, 1963). Intradermal injection of the antige in atopic individuals produces the very differeri. wheal and flair which is seen almost immediate upon injection. Thus it appeared that delayed ang immediate hypersensitivities could not co-exist to the same allergen in the same individual. The dẹ velopment of in vitro techniques for cell-mediated hypersensitivity has led to a reappraisal of this intef relationship. Brostoff \& Roitt (1969) using the lymphocyte-transformation test (Oppenheim, Wow. stencroft \& Gell, 1967) and macrophage-migration. inhibition (David Al-Askari \& Lawrence, 1964) werę able to demonstrate the immunologically specifiey allergized cells which mediate delayed hypersensiti vity in patients with summer hay fever. Furthermors they were able to reproduce a Type 4 skin reactiog by injecting the allergen along with an antihistamine. The existence in hay fever and asthma of cells capable of producing Type 4 tissue damage is not reflected i the pathological findings. Histologically the features shown in Fig. 1 do not resemble the granulomatous reaction associated with the delayed hypersensitienty Brostoff \& Roitt (1969) therefore interpreted ofhe presence of the allergized cells in the light of current concept of cell-cooperation. The lympho cytes involved in delayed hypersensitivity and the lymphocytes involved in antibody production boto arise from a common bone-marrow precursor cell but they can be immunologically separated. The former develop an antigenic marker by passage through the thymus and are called $T$ lymphocytef (Reif \& Allen, 1964). The B lymphocytes whick eventually produce antibody do not pass through the thymus. There is evidence to suggest that $i \bar{g}$. certain circumstances before the B lymphocytes can produce antibody, cooperation from the $\mathrm{T}$ lympho: cytes is necessary (Miller \& Mitchell, 1968). Thus the presence of $\mathrm{T}$ lymphocytes in conditions mediated by $\mathrm{IgE}$ is not mutually exclusive. Much of the work on cell cooperation is still to be confirmed, but nevertheless it seems that in atopic diseases more: than one allergic mechanism is probably involved

In order to keep a perspective I would like now too broaden my brief slightly and consider asthma as pattern of bronchial hyperreactivity which can be triggered by a wide range of stimuli. The knowf findings which need an explanation are the following

(a) the pathology and physiology of bronchial cons striction and the hyperreactivity of the bronchial tissue in asthmatic subjects to the action histamine, 
(b) immunologically why a specialized class of antibody is produced,

(c) eosinophilia and the concept of the 'shock organ',

(d) the close association of asthmatic attacks with respiratory infection,

(e) adrenalin tolerance and the effectiveness of bronchodilator drugs.

The anaphylactic guinea pig upon which the symptomatology of asthma was previously interpreted does not explain many of the above points and is therefore not a good experimental model. A better one is that proposed by Szentivanyi, Fishel \& Talmage (1963) i.e. the response in animals to the infection with Bordetella pertussis. It has been shown that in such animals the tissues are hyperreactive to histamine (Kind, 1958) and that the hyperreactivity extends to less specific stimuli like temperature (Munoz \& Schuchardt, 1957) and respiratory irritants (Fairchild, Bobb \& Thompson, 1966). Immunologically, Bordetella pertussis has a marked adjuvant effect (Munoz, 1964) and the antibody response includes antibodies of the reaginic type (Mota, 1958). There is also an increase in circulating eosinophils (Tjabbes \& De Wied, 1962). In contrast to the hyperreactivity to pharmacological mediators, the animals showed reduced susceptibility to catecholamines (Szentivanyi et al., 1963). It was claimed (Szentivanyi et al., 1963) that the pharmacological hyperreactivity is due to an imbalance of the two adrenergic receptor systems. They showed that if the uptake of peripheral glucose is inhibited by deprivation of normal $\beta$ adrenergic activity, then the tissues are more reactive to histamine. On the evidence afforded by the Bordetella pertussis mouse, Szentivanyi (1968) proposed that a similar adrenergic imbalance might account for the clinical manifestations of asthma. The main tenets of his hypothesis are that histamine and other mediators, if considered in their physiological role, are the natural chemical organizers of autonomic action. Consequently, non-immunological triggers of asthma would probably still act by utilizing the same mediators. Adjustment to their action requires activation of their natural antagonists - the catecholamines - and the balanced expression of the amines through the two adrenergic effector systems. If as Szentivanyi proposes, a genetic or an acquired block exists on the $\beta$ side, then $\alpha$ stimulation would be unopposed. In the context of asthma therefore, the bronchial tissue deprived of $\beta$-adrenergic stimulation would respond to unopposed $\alpha$ activity by constricting. Fig. 3 shows diagrammatically the major pathways postulated. Current thinking on the $\beta$ receptor associates it with an enzyme adenyl cyclase (Szentivanyi, 1968). In the presence of magnesium ions adenyl cyclase is activated by the catecholamines and catalyses the formation of $3^{\prime} 5^{\prime} \mathrm{AMP}$ and pyro-

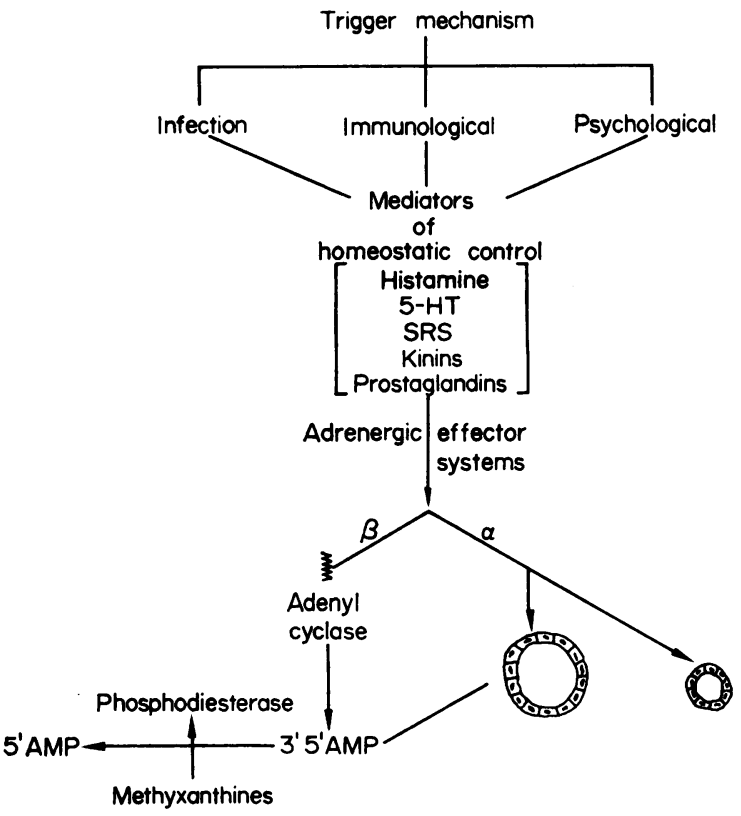

Fig. 3. Scheme outlining the $\beta$-adrenergic block hypothesis of the atopic abnormality. The jagged line represents the site of postulated blockage.

phosphate from ATP (Sutherland Robison, 1966; Belleau, 1966). The cyclic nucleotide then functions as an intracellular organizer of amine action. The inactivation of $3^{\prime} 5^{\prime} \mathrm{AMP}$ is brought about by a second enzyme phosphodiesterase, which can be inhibited by the methylxanthines. Thus these drugs exert their beneficial effect in asthma, by inducing adrenergic action distal to the hypothetical blockage. Time does not permit a more full analysis, but all the points listed earlier are explicable wholly or partially in terms of $\beta$-adrenergic blockade There is also experimental evidence to show that the immunological trigger, that is IgE/antigen interaction producing the release of histamine, works through the accumulation of intracellular cyclic AMP. Lichtenstein \& Margolis, 1968 demonstrated that the release of histamine from sensitized leucocytes could be prevented by the catecholamines and indeed by $3^{\prime} 5^{\prime}$ AMP itself (Ishizaka \& Ishizaka, 1970).

In conclusion therefore it is possible that both the intrinsic and extrinsic types of asthma have the same basic atopic abnormality. By differing in respect to their triggering mechanisms it appears clinically that each has a distinct aetiology.

\section{References}

Belleau, B. (1966) Steric effects in catecholamines interaction with enzymes and receptors. Pharmacological Reviews, 18, 131.

BenNiCh, H. \& Johansson, S.G.O (1967) Gamma globulin: Nobel Symposium III (Ed. by A. Killanda), p. 199. Interscience, New York. 
Boughton, B. \& Spector, W.G. (1963) Histology of the tuberculin reaction in guinea pigs. Journal of Pathology and Bacteriology, 85, 371.

Brostoff, J. \& RoITT, I.M. (1969) Cell-mediated (delayed) hypersensitivity in patients with summer hay-fever. Lancet, ii, 1269.

Coombs, R.R.A. \& Gell, P.G.N. (1963) Clinical Aspects of Immunology (Ed. by P. G. N. Gell \& R. R. A. Coombs). Blackwell Scientific Publications, Oxford.

DAVID, J.R., Al-Askari, S. \& LAWRENCE, H.S. (1964) Delayed hypersensitivity in vitro. I. The specificity of inhibition of cell migration by antigen. Journal of Immunology, 93, 274.

FAIRChild, E.J., BobB, G.A. \& Thompson, G.E. (1966) Enhanced toxicity of a respiratory irritant (ozone) by pertussis sensitisation. Federation Proceedings, 25, 692.

Figley, K.D. \& ElRoD, R.H. (1928) Endemic asthma due to castor bean dust. Journal of the American Medical Association, 90, 79.

IsHizAKA, K. \& IsHizaKA, T. (1970) The significance of immunoglobulin E. Annals of Allergy, 28, 189.

IsHIzAKA, T., IshIzAKA, K. \& Borsos, T. (1961) Biological activity of aggregated globulin. IV. Mechanisms of complement fixation. Journal of Immunology, 87, 433.

IsHIZAKA, K., IsHIZAKA, T. \& HORNBROOK, M.M. (1966) Physiochemical properties of reaginic antibody. V. Correlation of reaginic activity with $\gamma E$-globulin antibody. Journal of Immunology, 97, 840.

IshizaKa, T., IshizakA, K., ORANGe, R.P. \& Austen, K.F. (1970) The capacity of human immunoglobulin $E$ to mediate the release of histamine and slow reacting substance of anaphylaxis (SRS-A) from monkey lung. Journal of Immunology, 104, 335.

ISHIZAKA, K., ISHIZAKA, T. \& TERRY, W.D. (1967) Antigenic structure of $\gamma \mathrm{E}$-globulin and reaginic activity. Journal of Immunology, 99, 849.

IshizaKA, K. \& Newcomb, R.W. (1970) Presence of $\gamma$ E. in nasal washings and sputum from asthmatic patients. Journal of Allergy, 46, 197.

Ishizaka, K., Tomioka, T. \& Ishizaka, T. (1970) Presence of $\gamma$ and $\gamma \mathrm{G}$ molecules on human leucocytes. Journal of Allergy, 45, 98.

JoHANSSON, S.G.O. \& BENNICH, H. (1967) Immunological studies of an atypical (myeloma) immunoglobulin. Immunology, 13, 381 .

JoHANSSON,S.G.O., BENNICH, H. \& WIDE, L. (1968) A new class of immunoglobulin in human serum. Immunology, 14, 265.

KIND, L.S. (1958) The altered reactivity of mice after inoculation with Bordetella pertussis vaccine. Bacteriological Reviews, 22, 173.

Lichtenstein, L.M. \& Margolis, S. (1968) Histamine release in vitro: Inhibition by catecholamines and methylxanthines. Science, 161, 902.

LoWell, F.C \& SCHiller, I.W. (1948) Measurement of changes in vital capacity as a means of detecting pulmonary reactions to inhaled aerosolized allergenic extracts in asthmatic subjects. Journal of Allergy, 19, 100.
MilleR, J.F.A.P. \& Mitchell, G.F. (1968) Cell to cell inter气 action in the immune response. I. Haemolysin-forming cells in neonatally thymectomised mice reconstituted witli thymus or thoracic duct lymphocytes. Journal of Experi mental Medicine, 128, 801.

Mota, I. (1958) Mast cell and histamine in-rat anaphylaxis the effect of Haemophilus pertussis. Nature, 182, 1021.

MuNOz, J. (1964) Effect of bacteria and bacterial products in antibody response. Advances in Immunology, 4, 397.

MunOz, J. \& SchuchaRdT, L.F. (1957) Effect of Haemo philus pertussis on sensitivity of mice to cold stress Proceedings of the Society of Experimental Biology and Medicine, 94, 186.

OpPenheim, J.J., Wolstencroft, R.A. \& Gell, P.G.Nö (1967) Delayed hypersensitivity in guinea pigs to a proteinhapten conjugate and its relationship to in vitro transforma $\vec{\omega}$ tion of lymph node spleen thymus and peripheral blood lymphocytes. Immunology, 12, 89.

Reif, A.E. \& Allen, J.M.V. (1964) The AKR thymic antigen and its distribution in leukaemias and nervous tissues $A$ Journal of Experimental Medicines, 120, 413.

RowE, D.S. \& Wood, C.B.S. (1970) The measurement of serum immunoglobulin $E$ levels in healthy adults and children and in children with allergic asthma. Internationa 5 Archives of Allergy and Applied Immunology, 39, 1.

SCADding, J.G. (1969) Management of asthma. British Medical Journal, 3, 166.

Stanworth, D.R., Humphrey, J.H., BenNich, H. \& Johansson, S.G.O. (1967) Specific inhibition of the Praus nitz-Kustner reaction by an atypical human myelomaf protein. Lancet, ii, 330.

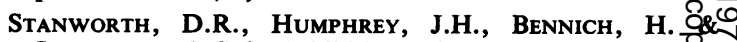
JoHANSSON, S.G.O. Inhibition of Prausnitz-Kustner action by proteolytic cleavage fragments of a hunfinc myeloma protein of immunoglobulin class E. Lancet, $\exists$ in 117.

Sutherland, E.W. \& Robison, G.A. The role of cyclic $3^{\prime} 5^{\prime} \overline{\bar{O}}$ AMP in responses to catecholamines and other hormones? Pharmacological Reviews, 18, 145.

Szentivanyi, A. (1968) The beta adrenergic theory of the atopic abnormality in bronchial asthma. Journal of Allergy 응 42, 203.

Szentivanyi, A., Fiscel, C.W. \& Talmage, D.W. (1963) Adrenaline mediation of histamine and serotonin hyperglycaemia in normal mice and the absence of adrenalineinduced hyperglycaemia in pertussis-sensitised mice. Journal of Infectious Diseases, 113, 86.

TJABbes, T. \& DE WIED D. (1962) The influence of ventral Pasteur hypothalamus on Bordetella pertussis vaccineinduced eosinophilia. Archives internationales de pharmaco-O dynamie et de thérapie, 135, 218.

WaldMan \& TERRY (1970) Quoted by Ishizaka, K. \&O IsHIZAKA, T. (1970) The significance of Immunoglobulin E. Annals of Allergy, 28, 189. 